\title{
Author Correction: QUAREP-LiMi: a community endeavor to advance quality assessment and reproducibility in light microscopy
}

Ulrike Boehm (1), Glyn Nelson (1), Claire M. Brown (D), Steve Bagley (D), Peter Bajcsy, Johanna Bischof, Aurelien Dauphin (1), Ian M. Dobbie (1D, John E. Eriksson, Orestis Faklaris (D), Julia Fernandez-Rodriguez (i), Alexia Ferrand (D),

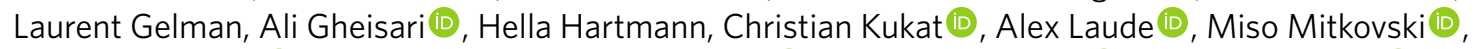

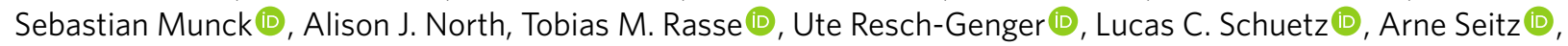
Caterina Strambio-De-Castillia (D), Jason R. Swedlow and Roland Nitschke (D)

Correction to: Nature Methods https://doi.org/10.1038/s41592-021-01162-y, published online 21 May 2021.

In the version of this article initially published, the affiliation for author Roland Nitschke was incorrectly formulated. The affiliation has been corrected to read "Life Imaging Center and Signalling Research Centres CIBSS and BIOSS, University of Freiburg, Freiburg, Germany" in the online version of the article.

Published online: 3 January 2022

https://doi.org/10.1038/s41592-021-01387-x

() The Author(s), under exclusive licence to Springer Nature America, Inc. 2022

\section{Author Correction: Micro-Meta App: an interactive tool for collecting microscopy metadata based on community specifications}

Alessandro Rigano, Shannon Ehmsen, Serkan Utku Öztürk, Joel Ryan (D), Alexander Balashov, Mathias Hammer, Koray Kirli, Ulrike Boehm (D), Claire M. Brown D, Karl Bellve D, James J. Chambers, Andrea Cosolo (D), Robert A. Coleman, Orestis Faklaris (D), Kevin E. Fogarty, Thomas Guilbert (D), Anna B. Hamacher, Michelle S. Itano (D), Daniel P. Keeley, Susanne Kunis (D), Judith Lacoste (D), Alex Laude, Willa Y. Ma, Marco Marcello (D), Paula Montero-Llopis (iD, Glyn Nelson (D), Roland Nitschke (D), Jaime A. Pimentel D, Stefanie Weidtkamp-Peters (D), Peter J. Park Di, Burak H. Alver, David Grunwald (iD) and Caterina Strambio-De-Castillia (D)

Correction to: Nature Methods https://doi.org/10.1038/s41592-021-01315-z, published online 3 December 2021.

In the version of this article initially published, the affiliation for author Roland Nitschke was incorrectly formulated. The affiliation has been corrected to read "Life Imaging Center and Signalling Research Centres CIBSS and BIOSS, University of Freiburg, Freiburg, Germany" in the online version of the article.

\footnotetext{
(c) (i) Open Access This article is licensed under a Creative Commons Attribution 4.0 International License, which permits use, sharing, adaptation, distribution and reproduction in any medium or format, as long as you give appropriate credit to the original author(s) and the source, provide a link to the Creative Commons license, and indicate if changes were made. The images or other third party material in this article are included in the article's Creative Commons license, unless indicated otherwise in a credit line to the material. If material is not included in the article's Creative Commons license and your intended use is not permitted by statutory regulation or exceeds the permitted use, you will need to obtain permission directly from the copyright holder. To view a copy of this license, visit http://creativecommons.org/licenses/ by/4.0/.
}

Published online: 24 December 2021

https://doi.org/10.1038/s41592-021-01388-w

(c) The Author(s) 2021 